\title{
The Key to Law Student Well-Being? We Have to Love Our Law Students
}

by David B. Jaffe

\begin{abstract}
This article is an effort to close the gap in the care provided to law students - offering concrete suggestions to take each of us beyond merely agreeing that more needs to be done to making a commitment to action.
\end{abstract}

Anyone paying attention has moved well beyond guesswork regarding the health of our law students. A recent survey focusing on law student well-being ${ }^{1}$ reflects, inter alia, that students are drinking excessively, ${ }^{2}$ are taking drugs not prescribed to them, ${ }^{3}$ and are expressing high rates of depression and/or anxiety. ${ }^{4}$ Another landmark study ${ }^{5}$ refutes earlier notions that these issues befall attorneys as they age, suggesting instead that younger attorneys are suffering in greater numbers, ${ }^{6}$ which in turn reflects a closer proximity to a lawyer's time in law school and underscores the importance of addressing these issues at an earlier time. Law school deans of students ${ }^{7}$ report increasing meetings and counseling of students (a good sign), which may reflect a coming of age of students who were diagnosed with a mental health issue or substance use disorder, as well as a greater self-awareness and desire for self-care than previously witnessed. However, these students are not seeking professional help for their issues in the numbers that would be anticipated. Unfortunately, after acknowledging that something more should be done to help these students, those who are able to make a difference often return to their own tasks and responsibilities, assuming someone else will address the myriad problems.

This article is an effort to close the gap in the care provided to law students. A National Task Force, convened to focus on well-being ${ }^{8}$ in the legal profession, developed a series of recommendations for critical stakeholders. ${ }^{9}$ Underscoring the recommendations, the Report is a "call to action" 10 at a critical juncture for those in the legal profession. This article focuses on the greater attention needed in law schools, ${ }^{11}$ offering concrete suggestions to take each of us beyond merely agreeing that more needs to be done to making a commitment to action. The article is thus divided into sections in an effort to address the many stakeholders who can play a role in taking better care of our students.

\section{Together we can make a significant difference in the lives of our law students; we have to start by loving them.}

After counseling thousands of law students, many of whom came forward only when in crisis and thus with reduced opportunities to help at the law school's disposal, I suggest that the time for strengthened approaches is upon us. Together we can make a significant difference in the lives of our law students; we have to start by loving them.

\section{Deans}

The Dean's role is critical to the success of almost every suggestion provided here. The Dean must establish the policy if it does not exist, or modify the policy if it is not addressing the needs of the school. Perhaps above all, however, the Dean must decide if well-being is to be among the mandates of governance. The Dean is the face of the law school and as such should be modeling what well-being looks like at the institution. The traditional prongs for assessment of law faculty - teaching, scholarship, and service - do not cater to the substantial needs raised in this article, perhaps because the needs are less traditional, and 
perhaps because they are less quantifiable. Whether choosing to expand on "service" to include regular non-classroom dedication to one's students, or to expand the prongs in a similar vein, the Dean is charged with making this work.

This article is a template from

which to consider where a law

school's contributions fall short and

how one might change them.

Start with an assessment. This article is a template from which to consider where a law school's contributions fall short and how one might change them. It also offers a PowerPoint ${ }^{12}$ to be used by the dean of students or designated official as a presentation to the faculty. When running through the presentation, pause to poll the faculty on what they believe is already implemented at the school; it may be surprising to learn what the faculty does and does not know about what the law school is (and is not) providing. This can be an instructive moment to discuss the importance of these issues and the support needed for effective implementation.

The Dean also should lead by example, such as by attending mindfulness sessions or other wellness programming when available. If teaching, the Dean should be sure to communicate in his or her own way the importance of the human element and of the well-being of the students, and find every opportunity - through internal meetings and with alumni - to support the efforts and extol the virtues of those who are taking the necessary steps in this area. Expressions of well-being and related actions are still considered to be "soft" in some circles, but those circles are reducing in size every day. Of significance to law schools, students are arriving with greater general selfawareness inclusive of diagnosed or recognizable issues; as a result, they in turn expect more of us each year. Deans should ensure that they are not falling behind in seeing to the needs of caring for their students.

\section{Admissions}

Law school admissions offices face an increasing challenge in filling entering classes that meet the competing demands of national rankings, diversity, and budgets. As data reflect a reduced number of applicants at the higher LSAT/GPA ranges, admissions officers may be more inclined to look past applications that suggest at-risk behaviors (i.e., multiple DUIs, certain criminal acts) to bring in the best class possible. While few would suggest that these individuals, if otherwise qualified, should not be admitted, admissions offices should at a minimum bring these candidates to the attention of someone at the law school for targeted, positive outreach. These students need to know that they are admitted unconditionally and that, should new stressors inherent to law school exacerbate preexisting conditions, they have one or more confidential resources to turn to. While acknowledging that for some admitted students this outreach may feel very personal, if not potentially invasive, a suggestion that a student engaged by a dean of students or relevant official will chafe at the sharing or exposure of information provided on an application should be outweighed by the greater connection resulting from that outreach. ${ }^{13}$ Students are asked to absorb a lot of information during their orientation, and as a result will benefit from this additional, targeted communication even if it is not needed until a later date, if at all. The communication should be viewed as one of respect and caring, and not of looking over the shoulder of the student.

\section{Orientation}

\section{While orientations continue by necessity to be jam-packed with information, the absence of a relevant conversation on this topic sends a signal that the school does not care, is afraid to take on the issue, or perhaps both.}

A conversation about mental health and substance use disorders and available resources to help students used to be 
considered taboo at law school orientations, since students were expected to hear only about the exciting transition and opportunities that awaited them in class and via experiential learning. Fortunately, it appears that most schools have adopted a more direct, hands-on approach toward these issues. While orientations continue by necessity to be jam-packed with information, the absence of a relevant conversation on this topic sends a signal that the school does not care, is afraid to take on the issue, or perhaps both. Going beyond the provision of a pamphlet in the back of a folder means slowing down the welcome - or some other moment - to acknowledge that new stressors will arise, that personal, emotional reactions to those stressors are normal, and that assistance should be sought at first indication and not delayed. ${ }^{14}$ Where possible, break up the entering class into smaller groups, and have a more in-depth conversation about these issues where there is greater likelihood of developing listening and responding. ${ }^{15}$

\section{Faculty}

Most faculty members are passionate about their teaching or their scholarship, and often both. This passion is only heightened when students engage and challenge them in the classroom and during their office hours. But not all students are immediately up to this level of engagement, for a number of reasons. Some are struggling with the issues being discussed in this article. Others are adjusting to being the first in their family to have reached this level of education, to accommodations for learning or physical disabilities, or to seeing grades they have never before received. Still other students are challenged by having an introverted personality at a time when the opposite is being sought, ${ }^{16}$ and/or simply by the new pace, language, and environment. These students often feel isolated and have an even harder time managing the personal issues they may have. Simultaneously, many faculty members are not trained in the art of engaging students beyond the Socratic method, bringing the imposition of personal conversations for both parties more sharply into focus.

\section{They might start small but powerfully by engaging students in the classroom on a personal level on a regular basis.}

Faculty members can change these dynamics to improve the student experience. They might start small but powerfully by engaging students in the classroom on a personal level on a regular basis. Faculty can consider inviting students at the start of the semester to share anything they would like the faculty member to know. Doing so opens the "door of humanity" right from the outset and lets students know faculty members care. Periodically throughout the semester, professors might spend a few minutes at the start or end of a class asking how students are; they may learn of a major assignment students are facing of which their other professors were unaware, or even of some issue among students that is causing levels of distress or disconnect. Engaging students at this (or any) time shows a professor's human side, which students will appreciate, and which may not come through as readily when a class appears focused solely on traditional case analysis. Faculty should be cognizant of and acknowledge competing demands on the students during peak times, such as for their $1 \mathrm{~L}$ writing assignments, moot court competitions, etc. Faculty members can let students know that some stress is normal and even okay, since it can spur an individual to action versus inaction. A faculty member who is willing to take this to a second level might set aside two minutes at the start of each class for meditation or some simple breathing exercises; faculty members who do this will be amazed at how much more attentive their students will be and at how much renewed energy students will have to engage with the faculty member. All told, faculty who let their students know that they care about them will, in turn, earn enhanced respect from students. At a time when faculty members lament their classrooms being occupied by students seemingly more interested in A's or their phones and social media, the opportunity to find ways to engage students is a win-win. 


\section{Attendance}

Deans of students often refer to the "badge of honor" in being on the front line when working with students near or in crisis. ${ }^{17}$ As much as we take pride in being available and being effective for situational counseling and appropriate referral to resources for badly needed assistance, the truth is that we have to rely on faculty members for our efforts to be successful. A student not showing up for class on multiple occasions is invariably a sign of a personal issue that is not being attended to. While the American Bar Association (ABA) failed to properly maintain attendance as a specified Standard worthy of tracking and assessing as a component of reaccreditation, ${ }^{18}$ that does not absolve us of ensuring that our students are okay. Every law school should have an attendance-keeping practice that is monitored, not for the sake of a policy, but for the health of its students - many of whom are away from support networks for the first time. Students are facing embarrassment, stigma, fear of not getting admitted to the bar, and related issues and are very unlikely to come forward if not asked to do so. From the tried-and-true passing of a sign-in sheet that is analyzed by the faculty member or an administrative assistant to more enhanced measures, ${ }^{19}$ failure to recognize the importance of monitoring our students' attendance is simply not an option. The dean of students should be prepared to communicate with any student over attendance issues, regardless of the basis for the inquiry. ${ }^{20}$

Schools have been inventive in providing reporting mechanisms for faculty (and staff, and students) if identification of the reporter remains a concern. One school utilizes an ongoing random email process for checking in generally with all students, through which a student who has been identified with a potential issue can be folded in, allowing for a more careful inquiry when the student arrives for the meeting. Another utilizes a "CARE" system whereby anyone can express an anonymous concern electronically; the dean of students' office then checks with other faculty or individuals known to the student to see if anything has been amiss. A third law school encourages its students to inform their dean of students ahead of an absence so that the office can inquire directly if necessary. Whatever the approach, a process must be in place to ensure that students are being looked after.

\section{Peers}

Peer volunteers are not expected to be trained as counselors; rather they are prepared to share their story and/ or ultimately direct the student to the resources he or she needs.

If you want to see a dean of students well up with pride and admiration, be on hand when a student shares that she is in recovery, and she would like to be open about it with any student she can assist. The Student Well-Being Survey ${ }^{21}$ highlights that despite significant numbers of law students needing help with mental health or substance use disorders, few will seek the assistance of their dean of students, ${ }^{22}$ fearing repercussions either within the school or for admission to the bar. ${ }^{23} \mathrm{Hav}$ ing students offer themselves as peer volunteers (or seeking them out by whatever means), providing them proper training inclusive of their obligation of confidentiality, ${ }^{24}$ and publicizing that the resource exists and is walled off from administrative oversight may provide the secure haven that students seek as a "formal" alternative. Peer volunteers are not expected to be trained as counselors; rather they are prepared to share their story and/or ultimately direct the student to the resources he or she needs. Expansions of this resource may include peer group sessions, development of alternatives to the traditional Thursday night "bar review," and the like. Motivated students might consider other programming, such as establishment of a student chapter for mindfulness meditation, ${ }^{25}$ a growing practice among law schools and generally for reduction of anxiety and related issues. 


\section{Counseling}

Not every law school is affiliated with a university or institution that can provide professional counseling. But every law school must ensure that its students have access to said counseling, particularly at a time that our students seem increasingly aware of their limitations and needs around mental health support. While utilizing a university's counselors provides a muchneeded resource and service, in many instances of situational ("on-the-spot") counseling, referral to a main campus does not yield the same result as the ability to have students meet counselors directly at the law school. Often students find excuses not to keep their appointment and make their way from one campus to the other. Moreover, the idea for some students that they cannot be seen by a provider at their law school creates an implicit stigma (i.e., "if I am not the only one with issues, why doesn't the law school provide services here?"). Many law schools provide dedicated counseling services to their students. A full-time counselor becomes part of the fabric of an institution and is able to provide additional outreach by creating law student-specific programming, as well as gaining perspective on the current needs of the population and of evolving conditions and circumstances. A full-time counselor also minimizes turnover, the need to identify new counselors, and potential delays and gaps in coverage during that period.

Finally, at a minimum, staff and faculty should know how to make referrals to state $\mathrm{LAPs}^{26}$ so a student has the full panoply of resources at his or her fingertips.

\section{Alcohol}

No proposed best practice seems more controversial than the reduction (or elimination) of alcohol at law school events. In a culture where the legal profession itself continues to celebrate accomplishments and the stress release with alcohol, it is challenging to suggest that scaling back within law school is not at best a temporary "timeout" and, at worst, a rationale to rebel against the school administration and continue to party without their support. The majority of law students are of legal drinking age, so dictating how they make their personal choices can certainly be viewed as inappropriately paternal. Despite this, there are benefits worth considering. Limiting alcohol on your campus signals to your students your recognition of the alcohol use problem in the profession as well as among law students. It also suggests to those students in recovery and those who are contemplating taking steps toward recovery that they have the support of the law school.

No proposed best practice seems more controversial than the reduction (or elimination) of alcohol at law school events.

It is time to take some responsible steps toward reducing the presence of alcohol on each campus. If you are losing the battle of absolute elimination of alcohol, one option is to allow for cash bars. If students who are hosting events balk at the lack of free access to alcohol for their non-law school speakers and guests, develop a prepaid ticketing plan for the guests. ${ }^{27}$ Alternatively, the host or law school can spend the money on elaborate mocktails that everyone can enjoy. ${ }^{28}$

\section{Alumni}

Many who read this article may not work at a law school. Law school graduates, or those working in the legal profession without having attended law school can yet have an influential role in caring for today's law students. Alumni have the power to make their voice known to their alma mater and can also be persuasive with their donations by asking for improvement in relevant areas and by providing funds to be earmarked for a relevant area described herein. Those in the profession can signal that resources around mental health and substance use disorders are among the checklist of expectations when considering law schools and their students. This would be a strong statement from outside the law school that caring for the students within is necessary. 


\section{A Final Word}

The foregoing is not intended as an a la carte menu of options. A law school dedicated to its students will make an effort on all fronts. The ABA may wish to consider adding to its accreditation standards a proper assessment of the well-being resources provided and actions taken by every law school rather than waiting for voluntary implementation. Other stakeholders such as boards of bar examiners should continue to review and revise their character and fitness questionnaires to avoid the chilling effect that invasive questions around mental health and substance use have on students seeking help while in law school. Together, greater expressions of love to our students and attention to their wellness and mental health can only result in these individuals experiencing more healthy and productive lives in law school and in the profession.

I am fairly certain that no student has accused his or her law school of caring too much. Perhaps it is time we changed that....

\section{Endnotes}

${ }^{1}$ J. M. Organ, D. B. Jaffe, and K. Bender, "Suffering in Silence: The Survey of Law Student Well-Being and the Reluctance of Law Students to Seek Help for Substance Use and Mental Health Concerns," 66 J. LEGAL EDUC. 116 (2016).

${ }^{2}$ Id. at $127-133$.

${ }^{3}$ Id. at $134-136$.

${ }^{4} I d$. at $136-138$.

${ }^{5}$ P. R. Krill, R. Johnson, and L. Albert, "The Prevalence of Substance Use and Other Mental Health Concerns Among American Attorneys," 10 J. ADDICTION MED. 46 (2016).

${ }^{6} I d$. at 48 .

${ }^{7}$ I use throughout this article "dean (or deans) of students" as the term of art applied to the individual in charge of seeing to the welfare of students at a given law school, recognizing that the title and position will vary from school to school.

${ }^{8}$ Depending on the individual and the context, "well-being" and mental health and substance use disorders are alternately conflated and distinguished. One fair application suggests that "well-being" relates to the proactive approaches taken in getting ahead of personal issues, such as by programming, advertising of available resources, and the like. Working on mental health and substance use disorder challenges does not preclude wellbeing approaches, but more typically reflects the response to issues when they arise.

${ }^{9}$ See "The Path to Lawyer Well-Being: Practical Recommendations for Positive Change," Report from the National Task Force on Lawyer Well-Being (August 2017).

${ }^{10} \mathrm{Id}$. at 10 .

${ }^{11}$ The author served as lead author for the Task Force Report on the law school section, portions of which are expanded upon within this article.

${ }^{12}$ PowerPoint on Mental and Emotional Wellness in Law Schools for use with faculty.

${ }^{13}$ The credibility of the communicator is important here. A dean of students, faculty member, or other official who has worked extensively on these issues and/or has to deal with such issues personally will help. One proposed communication: "Dear [Entering Student]: I join my colleagues in welcoming you to [law school] for what will be an incredibly rewarding experience. Because of my [extensive background in counseling students] [having undergone personal issues related to (depression/anxiety/substance use)], I review application files each year to ensure I have reached out to anyone whose past may suggest the possibility of challenges arising from new stressors in law school. This is not a judgment; it is merely an intended warm greeting from someone who cares about [his/her] students, with a pledge to receive you in a confidential, supportive setting should the need ever arise. In addition or alternatively, you have access to [university counseling services, the local lawyer assistance program, etc.]. I hope equally that you will not need these resources, and that you will take full advantage of them should the need arise, as many of your past classmates have and many of your current classmates will do."

${ }^{14}$ I suspect I am not the only one to share with the entering class that $90 \%$ of them will not graduate in the top $10 \%$. I do so in an effort to invite them to challenge themselves, but to understand that a top finish is not necessary and that establish- 
ing a pace that works for them at their level will serve them far better over the long haul.

${ }^{15}$ For the most recent Orientation at American University Washington College of Law, we chose to pair an administrator with one to two upper-level students for these break-out sessions. Students were phenomenal in sharing either their personal stories or those of classmates ("I was where you are now"), which really resonated with the entering class.

${ }^{16}$ Professor Heidi Brown offers powerful insights into the mindset of quiet law students and appropriate approaches toward engaging them in The Introverted Lawyer, American Bar Association, 2017.

${ }^{17}$ One of the nicest professional compliments I ever received was a faculty colleague stating she would never want my job. ${ }^{18}$ In 2015 the ABA adopted, over objection of many, a softer Standard than what was previously in place (compare the new "catch-all” Standard 308 (a) ("A law school shall adopt, publish and adhere to sound academic standards, including those for regular class attendance, good standing, academic integrity, graduation, and dismissal") with the former Standard ("A law school shall require regular and punctual class attendance").

${ }^{19}$ Several law schools have used or are exploring apps that allow for electronic attendance taking, such as by dropping a QR code onto a screen that the students scan by cellphone from their seats. Companies such as AppointLink, Involvio, and Top Hat have engaged schools in utilization of attendance tracking software.

${ }^{20}$ Meaning, you should err on the side of action in bringing attention to a student possibly in crisis. A properly trained dean of students will assess the situation and, even in the case of a "false alarm," most students will respect their school for having cared enough to reach out.

${ }^{21}$ See supra note 2.

${ }^{22} \mathrm{Id}$. at 140.

${ }^{23} \mathrm{Id}$. at 141.

${ }^{24}$ The local lawyer assistance program (LAP) or even an affiliated university counseling center should be able to provide assistance. LAPs provide free and confidential support and assistance to law students, lawyers, and judges who are facing issues around alcoholism, substance use disorders, or mental health issues. See The Directory of Lawyer Assistance Programs.

${ }^{25}$ The Mindfulness in Law Society is engaged in an ongoing effort to expand student chapters to every law school in the country.

${ }^{26}$ See supra note 24.

${ }^{27}$ Even here, however, one should be comfortable in drawing a line. There are fewer and fewer events of any type that have free-flowing alcohol; guests to your law school should understand your consistent approach.

${ }^{28}$ One law school provided the recipes for their mocktails at the reception, which resulted in animated conversations about those drinks rather than a lament over the absence of alcohol.

\section{About the Author}

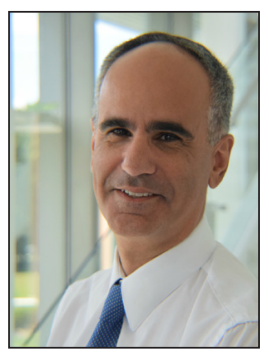

David B. Jaffe is Associate Dean for Student Affairs at American University Washington College of Law. In his work on wellness issues among law students over the last decade, he has served on the D.C. Bar Lawyer Assistance Program including as its chair, and continues to serve on the ABA Commission on Lawyer Assistance Programs (CoLAP) as co-chair of the Law School Assistance Committee. David co-authored "Suffering in Silence: The Survey of Law Student Well-Being and the Reluctance of Law Students to Seek Help for Substance Use and Mental Health Concerns," reporting the results of a survey he co-piloted in 2014. He was lead author for the law school section of "The Path to Lawyer Well-Being: Practical Recommendations for Positive Change" released in August. He also produced the "Getting Healthy, Staying Healthy" video that is used as a resource in many Professional Responsibility classes around the country, and is responsible for modernizing the "Substance Abuse \& Mental Health Toolkit for Law Students and Those Who Care About Them." 
David has presented frequently on law student wellness, including to the National Conference of Bar Examiners, The Professional Development Institute (PDI), the ABA Academic Deans, the ABA Young Lawyers Division, CoLAP, AALS, the D.C. Bar, and NALSAP. He received the 2015 CoLAP Meritorious Service Award in recognition of his commitment to improving the lives of law students, and the 2009 Peter N. Kutulakis Award from the AALS Student Services Section for outstanding contributions to the professional development of law students. David says he practices self-care by being in the moment with his daughters as often as possible. 